\title{
Experimental petrology: Quantitative boundaries for petrogenesis
}

\author{
PETER J WYLLIE \\ Division of Geological and Planetary Sciences, California Institute of Technology, Pasadena, \\ CA 91125, USA
}

\begin{abstract}
The paper is an overview of the current status on experimental petrology - its objectives and its major role in solving problems related to various earth processes. It describes how investigations related to solid-solid transitions, dehydration or decarbonation reactions, and melting studies have helped to formulate petrological models for the earth's internal structure. It also describes how measurements of physical properties of minerals, melts and vapour under extreme conditions have provided vital information on fluid dynamics of magmatic systems. The paper narrates the role of experimental petrology in calibrating geophysical processes with petrological consequences. Model P-T-X $\left(\mathrm{SiO}_{2}\right)$-fluid systems are considered to emphasize the role of various gas species in shifting the solidus in a P-T space, in degrees of melting and composition of the melt. Synthetic models and study of whole rock systems are considered to discuss the zonation and metasomatic processes in the mantle of the earth. The paper is also concerned with mantle convection and the uprise of thermal plumes, particularly, in the oceanic environment. It discusses the petrological structures associated with the plume and shows how static petrological maps are modified by the dynamics of the plumes.
\end{abstract}

Keywords. Petrogenesis; synthetic model systems, whole rock systems, mantle peridotite thermal structure, mantle plume.

\section{Introduction}

Petrology is the science of rocks, concerned with the processes leading to the distribution and diversity of rocks; this embraces the study of the minerals comprising them, and with geochemistry, the distribution of elements and their migration from one rock reservoir to another. Reservoirs may be considered on different scales, such as mantle/crust, different mantle layers, or dikes/country rocks, for example.

The classical approach to petrology is to study rocks at the surface, analyse them in detail, and to develop hypotheses regarding their origin at depth. A basic tool is the geological hammer, and petrologists attack mountains of rock with these small pieces of steel. This approach is now supplemented by the experimental approach, calibrating at high pressures in the laboratory the reactions expected to occur at depth. The petrologist takes a small sample of mineral or rock and crushes it, together with a furnace, in a massive steel press. For even higher pressures, a more delicate approach is adopted using even smaller samples squeezed between two minute diamond anvils, heated by laser. If these approaches fail to achieve the required conditions the more drastic approach of shock-wave experiments is adopted. The sample is blasted by a high-speed projectile, yielding its secrets only during the last hot nanoseconds of its existence. 


\subsection{Phase transitions and petrological processes}

Many of the important processes during the origin and evolution of the solar system and the Earth involve phase transitions, which occur in materials when they are subjected to changes in pressure and temperature. Experimental petrology is the laboratory study of the phase relationships of rocks and rock components (solid, liquid and vapour) through the range of pressures and temperatures to which they may be subjected in earth and planetary processes. The most important types of phase transitions in these processes are (i) solid-solid transitions, (ii) dissociation reactions such as dehydration or decarbonation reactions, and (iii) melting reactions. These are reversible reactions, covering processes of (i) recrystallization in response to pressure-temperature changes in any direction, (ii) hydration, carbonation, oxidation, etc., and (iii) crystallization of liquid. Other reactions involve open systems where (iv) fluids (melts, hydrothermal solutions, or vapours) are added to a rock system, causing chemical changes in addition to phase transitions.

Petrological processes are firmly rooted in geophysics, and perturbation of a thermal structure by dynamic processes causes phase transitions to occur at positions defined by the experimentally determined phase transitions. Processes occurring too rapidly or at too low a temperature, however, may not reach equilibrium, and the preservation of incompletely reacted minerals may reveal information about the history of the changes in depth and temperature experienced by the rock body. Experimentalists normally strive to reach equilibrium in the determination of phase diagrams for mineral or rock system, but there is a developing field of kinetic studies of reactions at high pressures and temperatures.

The results of experimental petrology also provide the geometrical representation of the chemical thermodynamics of a system, and the interplay of experiment and theory has been a powerful combination. Advances in techniques for calorimetry measurements of minerals synthesized at high pressures have provided critical thermochemical data for thermodynamic calculations at high pressures and temperatures.

Experimental petrology is also concerned with measurements of the physical properties of minerals and melts and vapours under extreme conditions, and this provided vital information for recent advances in studies of the fluid dynamics of magmatic systems. The objectives of experimental petrology stated in terms of definition of the pressure-temperature-composition variations and the physical properties of mineral, melts and vapours illustrate its role as the materials science of the Earth. There is a wide range of experimentation in topics such as the structure of glasses, and the effect of pressure or dissolved volatile components on the structures of silicate melts, and diffusion rates of trace elements and volatile components in glasses and melts.

The information that can be gained from experimental samples has been greatly expanded in recent years by improvement in techniques for microanalysis. Automated electron microprobes, ion microprobes, scanning electron microscopes with analytical capabilities, Fourier transform infrared instruments, and others reveal details that were invisible to $\mathrm{X}$-ray diffraction and optical microscope - the main tools in earlier days. Development of the capability for in situ measurement of optical, X-ray and spectroscopic properties in some apparatus during an experimental run is almost like science fiction. It is certainly great science.

Another aspect of experimental petrology that has appeal is that of exploration. 
Many of the reactions and effects that have been discovered in the study of phase relationships at high pressures and temperatures had not been predicted.

\subsection{Petrological applications}

Phase transitions occur in rocks subjected to changes in pressure (depth), temperature, or composition. Pressure varies if a mass of rock moves up or down as in solid state convection in the mantle, or through subduction of lithosphere, or through uplift or subsidence of a crustal region, as in mountain building. Temperature may change through influx of heat (perhaps by influx of hot fluid), loss of heat, or physical displacement of a rock mass. Composition may change by flux of magma or of solutions.

The results of experimental petrology calibrate the geophysical processes which have petrological consequences. Applications span the whole range of conditions through the crust, the mantle, and now even into the Earth's core, with recent super-high pressure experiments attaining conditions within the large gaseous planets. The positions of phase boundaries provide specific depth-temperature limits for many processes or formation of particular mineral assemblages (rocks). They provide calibrations for processes. The phase boundaries, and the properties of the materials within the boundaries, have been applied to earth processes with greatest success when used in conjunction with information from seismology, geochemistry and tectonics.

Topics of particular interest in recent years include the composition and mineralogy of the mantle, the formation of magma oceans, the origin of continental crust, the generation of basalts at oceanic ridges and hot-spots, the generation of andesites and batholiths at convergent plate boundaries, the metamorphism of crustal rocks during plate collisions and orogenesis, the generation of volatile-rich continental rocks such as kimberlites and carbonatites, the crystallization and differentiation of magmas, the origin of ore deposits, and interactions between fluids and rocks at conditions ranging from mantle metasomatism to submarine hot springs. The physical aspects of these topics involving the properties of materials and fluid dynamics, range from a solid mantle with traces of interstitial fluid, to crustal migmatites with a moderate content of viscous melt, to mixing of magmas, to double-diffusive convection in composite magma chambers, to mineral accumulation in magma chambers, to volcanic eruptions from magma chambers with suspended minerals.

\section{Experimental approaches}

Experimental approaches to petrogenetic problems in metamorphic and igneous petrology include the following: (i) determination of the phase diagrams for individual minerals, (ii) determination of the phase relationships of mineral assemblages representing simplified rocks, (iii) determination of the phase relationships in ternary or quaternary systems that include the rock-forming minerals, (iv) determination of the phase relationships in whole rocks, including possible source rocks as well as possible derivative magmas compositions, and (v) determination of the phase relationships in genetically related rock series.

Phase equilibrium studies form an important basis for interpretive petrology. The simple silicate systems that can be treated theoretically in terms of the phase rule 
establish patterns of behavior that must be considered in the development of petrogenetic theories. However, it is a long extrapolation from these systems to the complex rock systems, and the study of natural rock samples in the presence of one or more volatile components provides useful stepping stones between the synthetic and natural systems. The study of a single rock sample is analogous to the study of a single bulk composition within a complex multicomponent phase diagram, whereas the study of a series of genetically associated rocks represents a linear slice through the phase diagram.

\subsection{Synthetic model systems and whole rock systems}

The simple model systems provide detailed insight into possible processes, with all phases and variables under control and visible. Phase proportions may be varied at will as different parts of the phase diagram are determined. But the systems lack components compared with the real rocks, components that may prove to have a critical influence. In the study of multicomponent rock systems, there may be difficulty in controlling bulk composition, especially for volatile components present in small quantities, and for $\mathrm{Fe}$, and in the unambiguous identification and analysis of phases present in small amounts. In complex multimineral systems, it is more difficult to achieve and prove the attainment of reversible equilibrium. Experimental strategies have been devised to reduce these problems.

Simple synthetic systems have proved to be indispensable models for complex rock systems. Some phase relationships worked out in the model systems would be extraordinarily difficult to unravel in rock systems. On the other hand, minor components in rock systems have revealed phase relationships that do not occur in the simple model systems without these components. The parallel study of both types of system is required for comprehension of the phase relationships and processes illuminated by the experiments.

\subsection{Variety of results}

For metamorphic petrogenesis, the main results are: (i) the positions of reaction boundaries, solid-solid, dissociation through the melting reactions that occur in high grade rocks, (ii) the compositions of coexisting mineral in assemblages that occur in facies between the reaction boundaries, along with (iii) the partition coefficients of elements among minerals which may be calibrated to yield geothermometers and geobarometers. Recent measurements of isotope variations in large-zoned metamorphic garnets, as well as calculations on rates of temperature variation associated with thickening or thinning crust, provide another dimension; after decades of calibrating deep processes in terms of depth and temperature, petrologists and geochemists are now developing depth-temperature-time paths for mountain ranges.

For igneous petrogenesis, the main results include: (i) the conditions for the beginning of melting of possible source rocks in mantle or crust, (ii) the percentage of melt produced as a function of temperature above the solidus, and how this varies as a function of pressure, (iii) the composition of the melt as a function of temperature and pressure, (iv) the effect of volatile components such as $\mathrm{H}_{2} \mathrm{O}$ and $\mathrm{CO}_{2}$ on the solidus temperature, and on melt composition, (v) the effect of oxygen fugacity on these same features, and on the compositions of Fe-bearing minerals, and (vi) the 
crystallization paths of various melts through the range of variables already listed. These results require, for application to processes, information about the physical behaviour of rock-melt-vapour systems through a range of pressures and temperatures.

There are many more specialized types of experimental petrology. Interpretation of a majority of ore deposits, for example, requires concentration on sulphide and oxide systems, and the influence of additional volatile components such as halogens becomes more important. Other processes require the study of solution chemistry at high pressures and temperatures with a very high proportion of volatile components. Experimental petrology of the Earth's core involves the phase relationships of molten metal, and for the gaseous planets emphasis is on hydrogen, ammonia and methane. Revolutionary advances are being made in super-high pressure studies with applications to deep planetary interiors.

\section{Selected phase diagrams and their uses}

\section{$3.1 \mathrm{P}-\mathrm{T}-\mathrm{X}$ phase diagram for rock- $\mathrm{H}_{2} \mathrm{O}$ system}

The main variables for representing the phase relationships are pressure, temperature and parameters for composition. For a single mineral or rock, the fusion conditions are represented by a univariant curve or melting interval with a positive slope, $\mathrm{d} P / \mathrm{d} T$, as shown in figures $1 \mathrm{C}$ and 2 . The solidus curve is lowered by solution of volatile components under pressure, and the large effect of $\mathrm{H}_{2} \mathrm{O}$ is illustrated in figures $1 \mathrm{E}$ and $F$.

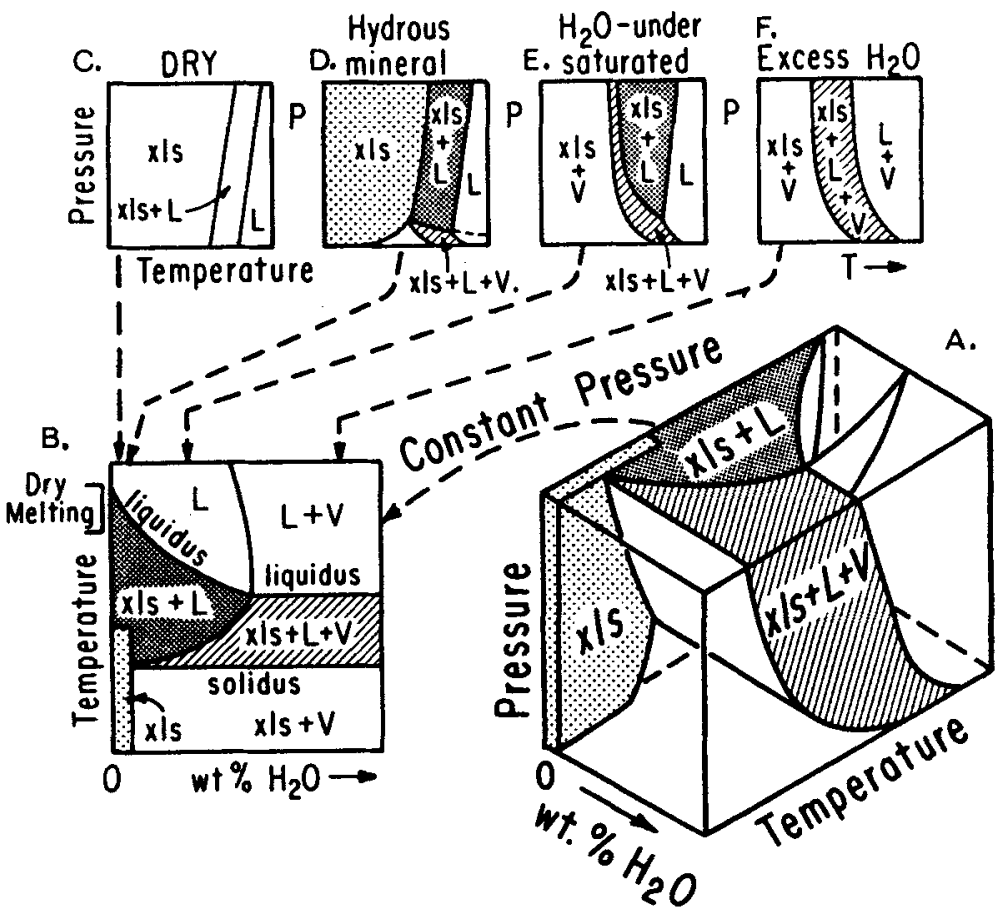

Figure 1. Phase relationships for a single rock composition, showing the effect of $\mathrm{H}_{2} \mathrm{O}$ represented within a $\mathrm{P}-\mathrm{T}-\mathrm{X}\left(\mathrm{H}_{2} \mathrm{O}\right)$ model, and illustrated by isobaric and isoplethal (constant $\mathrm{H}_{2} \mathrm{O}$ content) sections through the model (Wyllie 1988a). 


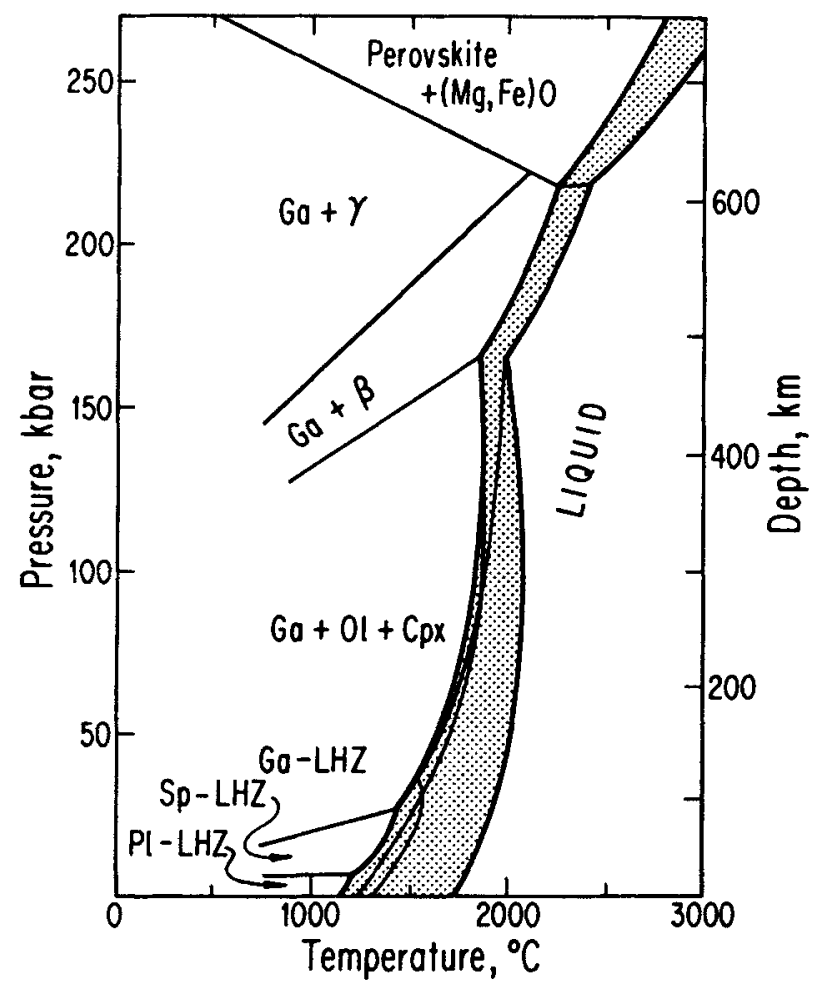

Figure 2. Experimentally determined phase diagram for peridotite (Takahashi 1986). Compare figure IC. Abbreviations: LHZ, lherzolite; Pl, plagioclase; Sp, spinel; Ga, garnet; $\mathrm{Ol}$, olivine; Cpx, clinopyroxene; beta and gamma are high-pressure polymorphs of olivine. The stippled band is the melting interval.

For the mantle and crust, representative phase relationships can be illustrated in silicate- $\mathrm{H}_{2} \mathrm{O}$ systems. The simplest and most convenient geometrical framework for experimental data on rocks, considering the variables that can be measured and controlled in the laboratory, is $\mathrm{P}-\mathrm{T}-\mathrm{X}\left(\mathrm{SiO}_{2}\right)-\mathrm{X}\left(\mathrm{H}_{2} \mathrm{O}\right)$. For an individual rock $\mathrm{X}\left(\mathrm{SiO}_{2}\right)$ is constant, and the framework is reduced to the three-dimensional model P-T-X( $\left.\mathrm{H}_{2} \mathrm{O}\right)$ illustrated in figure 1. In order to trace geological processes for a given rock, we should follow polybaric-polythermal paths through the phase volumes in figure 1A, which is graphically difficult. However, the types of processes can be illustrated in isobaric or isothermal diagrams. This is too complicated for convenient viewing, and the results are commonly presented in sections through the model.

Figure $1 \mathrm{~B}$ is an isobaric $\mathrm{T}-\mathrm{X}\left(\mathrm{H}_{2} \mathrm{O}\right)$ section. Note the three different solidus temperatures, one for excess vapour, one for a rock with all $\mathrm{H}_{2} \mathrm{O}$ stored in a hydrous mineral, and one for the completely anhydrous rock without any hydrous minerals. Note also the large area for $\mathrm{H}_{2} \mathrm{O}$-undersaturated liquid with crystals.

Isoplethal sections through the model in figure 1A provide four types of P-T diagrams corresponding to different ranges of $\mathrm{H}_{2} \mathrm{O}$ contents. Each of these is correlated in figure 1 to the isobaric section, figure $1 \mathrm{~B}$. Figure $1 \mathrm{C}$ and $\mathrm{F}$ represent the familiar extremes for the melting interval of a rock either completely anhydrous or with excess $\mathrm{H}_{2} \mathrm{O}$. Figure 1D represents a rock without pore fluid, but with some $\mathrm{H}_{2} \mathrm{O}$ stored in 
hydrous minerals. The solidus curve at low pressures is the same as that for figure $1 F$. At higher pressures, however, the solidus corresponds to the reaction where the hydrous mineral breaks down, providing $\mathrm{H}_{2} \mathrm{O}$ for solution in $\mathrm{H}_{2} \mathrm{O}$-undersaturated liquid. Figure 1E represents a rock system with hydrous minerals and subsolidus vapour, but with insufficient $\mathrm{H}_{2} \mathrm{O}$ to saturate the liquid. The solidus is the same as that in figure $1 \mathrm{~F}$, but the melting interval includes a large area of crystals.

\subsection{Effects of $\mathrm{CO}_{2}$ and $\mathrm{H}_{2} \mathrm{O}$ on melt compositions}

Diagrams similar to figure 1 can be constructed for silicate- $\mathrm{CO}_{2}$ systems. There are significant differences, however, because the solubility of $\mathrm{CO}_{2}$ in silicate melts is much lower, and the depression of the solidus temperature is therefore correspondingly less. If the mineralogy is suitable for the occurrence of carbonation reactions with increasing pressure (as it is for peridotite), the amount of $\mathrm{CO}_{2}$ that can be stored in the rock is much higher than that associated with hydration of the same rock. In this case, the solidus curve drops abruptly within a narrow pressure interval, where the carbonate becomes stable on the solidus. This is associated with change in the liquid composition along a path toward enrichment in carbonate, accompanied by decrease in $\mathrm{SiO}_{2}$, in contrast, it has been established that with solution of $\mathrm{H}_{2} \mathrm{O}$ the liquid composition is enriched in $\mathrm{SiO}_{2}$.

\subsection{Phase diagram for mantle peridotite}

The Earth's mantle has composition corresponding to that of peridotite, and this is therefore the most abundant rock on Earth. The crust was derived by chemical differentiation from the mantle, and the phase relationships of peridotite thus represent a good starting place in experimental petrology. There have been many experimental studies on various aspects of the phase relationships of peridotites, lherzolite and harzburgite, with most experiments limited to pressures of about $40 \mathrm{kbar}$. The persistence and ingenuity of Japanese scientists with the development of massive presses and relatively large-volume high pressure experiments has been rewarded recently with Takahashi's (1986) most extensive phase diagram for lherzolite as illustrated in figure 2 . The diagram shows phase relationships determied for a lherzolite up to pressures of $200 \mathrm{kbar}$. Recent results in USA with the diamond-anvil apparatus using perovskite as a model for the mantle composition have extended the solidus curve between pressures corresponding to $650-2000 \mathrm{~km}$ depth in the Earth's mantle, about $2 / 3$ of the way to the core. This is a remarkable increase in our range of knowledge.

Figure 2 (compare figure 1C) shows subsolidus phase changes involving increases in density with increasing pressure. At pressures corresponding to a depth of about $650 \mathrm{~km}$, where there is a seismic discontinuity, it appears that most mantle components find a comfortable home in the mineral structure of perovskite. There are distinçtive cusps on the solidus associated with the subsolidus phase changes, where the aluminous minerals change from plagioclase at low pressure, to spinel, and to garnet at pressures corresponding to depths of about $75 \mathrm{~km}$.

The solidus curve for the beginning of melting is the most important phase boundary in connection with chemical differentiation of the Earth. Its position provides a constraint that must be satisfied in schemes for convection and magma generation. 
The composition of the melt produced within the melting interval above the solidus varies as a function of pressure and temperature. Debates about the melt compositions have abated as divergent experimental results and interpretations have converged with those of computations. As noted above, the presence of volatile components can change both the solidus temperature (figure 1D-F) and melt composition.

\subsection{Phase diagrams in forward and inverse approaches}

Figure 3 outlines some of the ways that phase diagrams for minerals and rocks may help to decipher the processes occurring between the partial melting of the inferred source rocks and the observed magmatic products. The forward and inverse approaches have been applied extensively to the generation of basalts from the mantle sources.

The phase equilibrium data for rocks and magmas provide a set of constraints that can be used in the following ways as outlined in figure 3: (i) to define the mineralogy of possible source rocks as a function of depth; (ii) to define the compositions of liquids produced from possible source materials; (iii) to define polybaric polythermal paths of crystallization or differentiation; (iv) to determine, in conjunction with geochemical data, which composition in an igneous suite represents the primary or most primitive liquid; and (v) to determine the conditions under which specific liquid compositions could coexist with residual minerals in a source rock. These approaches,

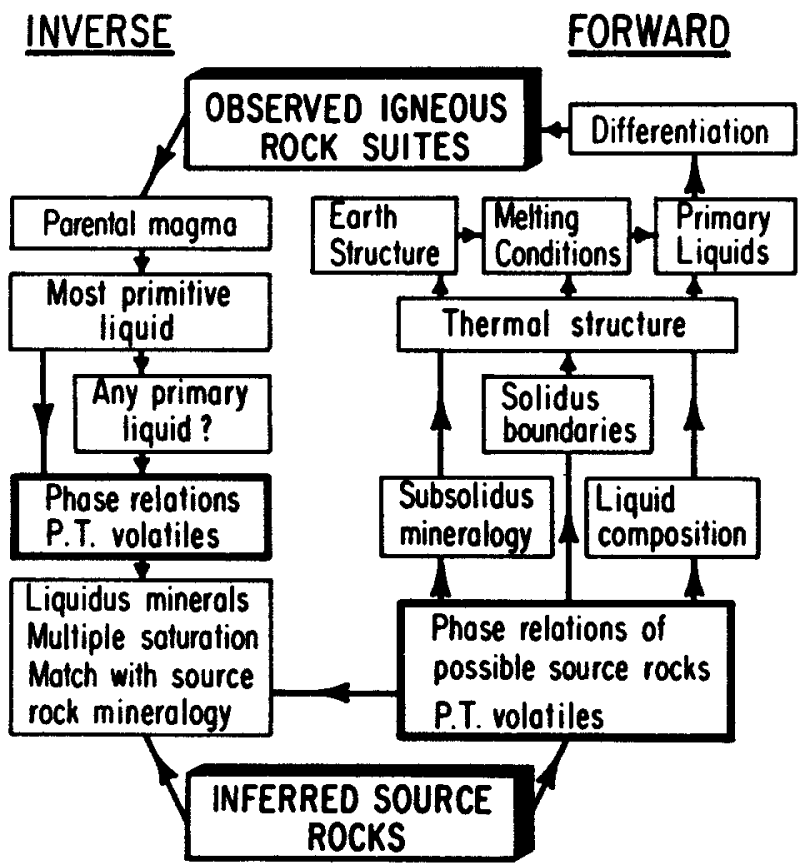

Figure 3. Inverse and forward approaches for testing the relationships between an observed suite of igneous rocks, and the inferred source rocks at depth. Experimental petrology of the materials, used in conjunction with geochemistry and geophysics, provides information about, and places constraints on the Earth's mineralogy and structure, and the sources and histories of magmas (Wyllie 1984). 
in combination with the thermal structure within the Earth, provide a means to test geophysical and petrological models in different tectonic environments. Forward and inverse approaches supplement each other.

In the forward approach, the phase relationships of the assumed source peridotites are determined, and the compositions of liquids generated are measured. Conditions are sought where the liquid have compositions obviously related to erupted lavas. Figure 3 shows the other types of results obtained, such as the subsolidus mineralogy. Comparison of the properties of these mineral assemblages with mantle properties determined from seismology leads to deductions about mantle mineralogy and structure.

In the reverse approach, the most primitive lava from a suite is selected, and its phase relationships determined under a variety of conditions. If this composition was derived from peridotite at depth and erupted to the surface as a primary magma (without significant differentiation en route to the surface), then the minerals left behind in the source rock should be liquidus minerals for the lava, under the P-T-X conditions at the place of origin. This approach leads to estimates of the depth and temperature of the last equilibration of the lava, before uprise and eruption. Data such as this can be correlated with models for mantle convection, based on seismology and geochemistry. Interpretation of geochemical analyses of magmatic products in terms of the chemistry of source rocks is an inverse approach.

\section{Distribution of vapour and melt in a mantle plume}

Many features of the general statements made above about experimental petrology can be illustrated in the uprising parts of mantle convection. The major chemical differentiation of the Earth is accomplished by separation of basalt from mantle peridotite. This occurs where solid mantle material rises up beneath (i) continental rift valleys, (ii) oceanic ridges, or in (iii) thermal plumes associated with hot-spots, such as Hawaii or Yellowstone.

The island of Hawaii is composed of a huge pile of basalt extruded within a few million years, and the process has been continuing for tens of millions of years, as shown by the track of seamounts extending northwest from the Hawaiian islands. In order to understand the processes that have produced so much basalt through so many years, we need to know at least the following: (i) the thermal structure in the mantle, and its variation with time, (ii) the source rocks at depth, (iii) the phase relationships of the source rocks and the basaltic products, (iv) the geophysical and petrological processes occurring between the source and the surface, and (v) the physical behavior of rock-melt-vapour systems from the source to the surface. Melting occurs if physical conditions raise the geotherm across the solidus, or if addition of volatile components lowers the solidus curve to temperatures below the geotherm.

\subsection{Thermal structure and phase relationships}

Consider an oceanic environment, uncomplicated by the presence of continental crust, with uprise of a thermal plume in the mantle generating a hot-spot at the base of the lithosphere. Figure 4 shows the general arrangement of isotherms.

Figure 2 shows the phase relationships for a mantle of uniform lherzolite, and the 


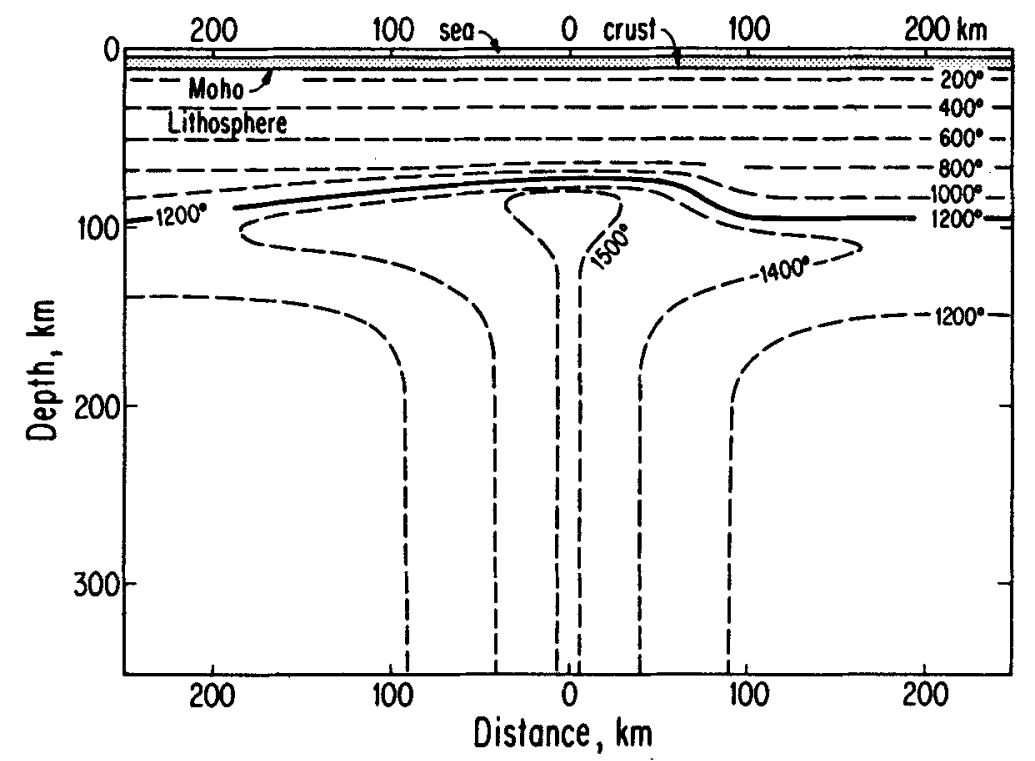

Figure 4. Schematic isotherms for a mantle plume beneath oceanic lithosphere, based on plumes of Courtney and White (1986), and the requirement for meiting of peridotite below the lithosphere at $1500^{\circ} \mathrm{C}$ (compare figure 2). Asymmetry is caused by motion of the lithosphere plate across the plume. The change in rheology associated with the asthenospherelithosphere boundary layer is arbitrarily represented by the heavy line for the $1200^{\circ} \mathrm{C}$ isotherm.

solidus curve is reproduced in figure 5 . Even the most primitive of lavas contain traces of dissolved $\mathrm{H}_{2} \mathrm{O}$ and $\mathrm{CO}_{2}$ derived from the mantle sources. What proportions of these volatile components are primordial and what have been recycled via subduction remain to be established.

The mantle's oxygen fugacity at different depths and its effect on the solidus for lherzolite- $\mathrm{CO}_{2}-\mathrm{H}_{2} \mathrm{O}$ are controversial, but the solidus given in figure 5 will serve to illustrate the processes. A distinctive feature is the ledge at about $80 \mathrm{~km}$ associated with the formation of dolomite and amphibole. The presence of volatile components lowers the solidus curve, changes the composition of the melts, and introduces new hydrated or carbonated minerals. There is experimental evidence that the curve rises to higher temperatures with decreasing oxygen fugacity. Two curves show deep hydration and carbonation reactions. Lherzolite minerals will absorb all $\mathrm{H}_{2} \mathrm{O}$ and $\mathrm{CO}_{2}$ at these reactions to generate brucite, magnesite, and DHMS (dense hydrous magnesian silicates). If conditions are reduced, then $\mathrm{CH}_{4}$ and perhaps $\mathrm{H}_{2}$ can persist as a vapour phase to deeper levels.

The composition of the near-solidus liquid generated by partial melting of peridotite- $\mathrm{CO}_{2}-\mathrm{H}_{2} \mathrm{O}$ at depths greater than $75 \mathrm{~km}$ is carbonatitic, dominated by calcic dolomite, with concentration of alkalis according to availability, and with silicate components about $10 \%$. This liquid becomes enriched in silicate components with increasing temperature, and perhaps with depth.

\subsection{Petrological structure}

Each point in the thermal plume of figure 4 is characterized by a specific pressure 


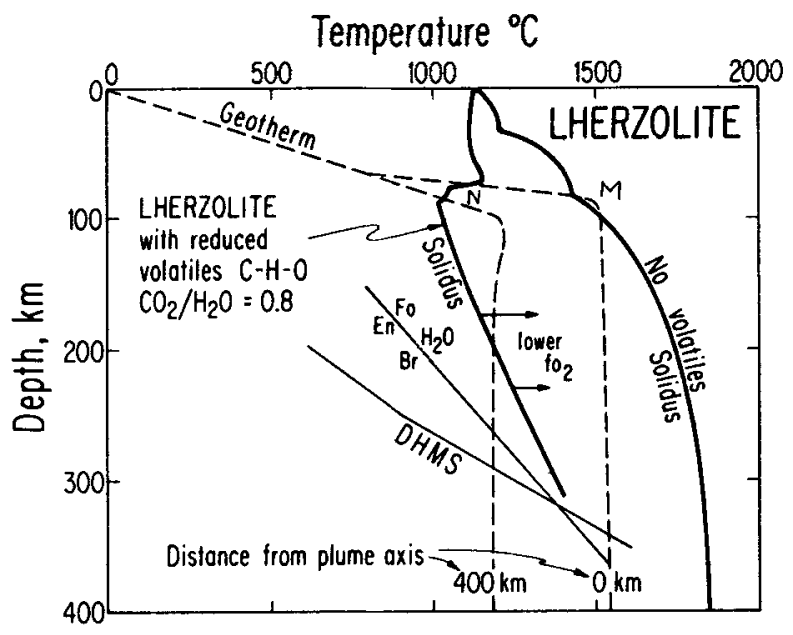

Figure 5. Solidus curve for lherzolite from figure 2, volatile-free, compared with a curve for the solidus in the presence of $\mathrm{H}_{2} \mathrm{O}-\mathrm{CO}_{2}$; this curve moves to higher temperatures under reducing conditions. The position of this curve between 70 and $100 \mathrm{~km}$ varies according to volatile content, oxidation state, and alkali content of the mantle; all of these factors are uncertain and variable. Two deep hydration and carbonation reactions are shown for mantle minerals (DHMS = dense hydrous magnesian silicates). The two geotherms correspond to positions at the axis and $400 \mathrm{~km}$ away from the axis of the plume in figure 4 . Note the large area at temperatures above the solidus for peridotite-volatiles, and the small area at $\mathrm{M}$ where the volatile-free mantle would melt (Wyllie 1988a).

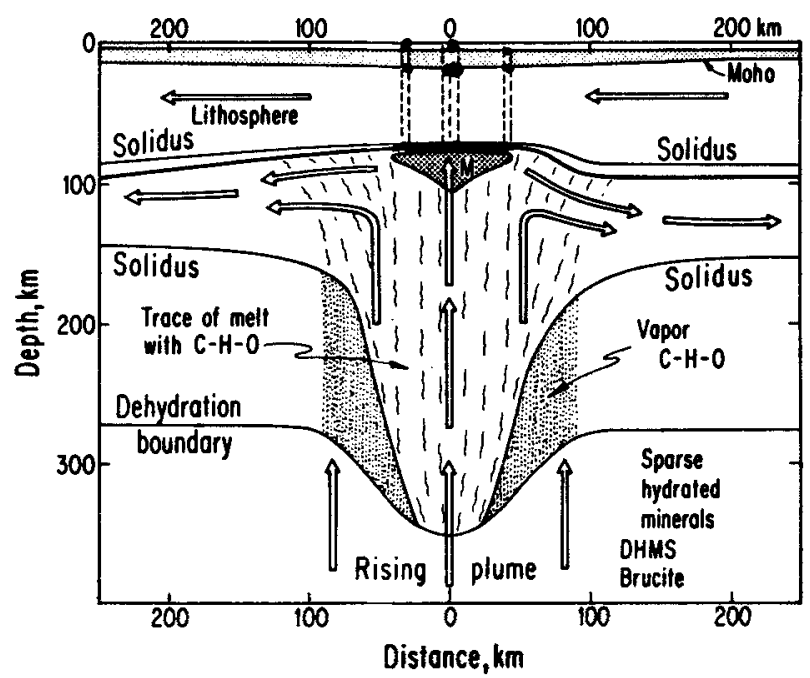

Figure 6. Petrological structure below Hawaii based on isotherms in figure 4, and the phase boundaries in figure 5. Material following flow lines crosses the phase boundaries, causing the distribution of vapour and melt in rising plume as shown. Major plume melting occurs at $\mathbf{M}$ (compare figure 5), and magma chambers form at various levels. Within the rising plume, above the dehydration boundary, there is a sheath of vapour surrounding a core of volatile-rich melt, and a relatively small kernel of significantly melted mantle. The volumes of the sheath and core vary according to the temperatures in the plume, and the position of the solidus for peridotite-volatiles in figure 5. Figure 7 shows more details in the region of the asthenosphere-lithosphere boundary layer (Wyllie 1988b). 
and temperature. All phase boundaries from figure 5 may therefore be plotted on the mantle isotherms, providing the petrological cross-section in figure 6 .

Consider the processes occurring when the mantle plume rises through this petrological map. In the deepest layer there is no vapour phase, although with reduced oxygen fugacity methane and perhaps hydrogen may occur. A rising plume carries mantle across the dissociation boundary releasing a separate vapour phase. At a shallower level this is carried across the solidus for peridotite-volatiles, and a trace of interstitial volatile-rich liquid is generated. Only in the highest part of the plume does significant melting occur, and picrite liquids are formed in the asthenosphere in the area $M$. The percentage of melt increases as the rock temperature rises further above the solidus, reaching perhaps $25 \%$, the amount depending on the maximum temperature within $M$ (figures 4 and 5).

If equilibrium were maintained the amount of liquid would decrease as the plume is carried out of the melting region $M$ on either side. In fact, the melt rises through the rock matrix and either forms magma chambers at the base of the lithosphere, or rises directly into shallower magma chambers beneath the volcanoes. The physical details are not established. Prospects for additional melting of lithosphere appear to be limited. The melt composition is picrite, its viscosity is very low, and the dihedral angle is low enough that percolation should occur at a relatively rapid rate. Uprise through the lithosphere may include both percolation and transport through cracks. The petrological structure of a mantle plume reveals an outer sheath containing a vapour phase, a core with a trace of melt, and a shallow kernel with extensive melting yielding picrites or basalts, depending on the depth. The size and shapes of these volumes may be changed, according to variations in oxygen fugacity in the mantle, and experimental determinations of solidus positions as a function of the mantle variables.

\subsection{Dynamic considerations}

The static petrological maps are modified by dynamics of the plume, because of thermal effects associated with the phase changes, and by differential movement of vapours and magmas. Latent heat effects will change the distribution of isotherms and thus shift the positions of phase boundaries. Differential movement of material such as escape of lava from the top of the plume will change bulk compositions and thus the positions of phase boundaries. The precise geometry of the petrological structure will thus be changed, but the general distribution of phase volumes is suitable for illustration of processes.

It is desirable to feed these modifications into the problem. The framework of phase boundaries appears to be robust enough to accommodate adjustments, and it is precisely through such adjustments arising from the interplay of geochemistry, fluid dynamics, and experimental petrology that we may advance our understanding of processes. What is needed is a complete dynamic treatment, with flow lines, which should include buoyancy-driven circulation resulting from magma separation from the plume. We need more information about the migration of fluids by percolation or fracture. Recent experimental studies on dihedral angles or "wetting angles" between minerals and fluids is relevant in this respect.

The viscosity of all liquids associated with the plume is very low, and the interfacial angles for the volatile-rich liquids are well below $60^{\circ}$, so they would form interconnect- 


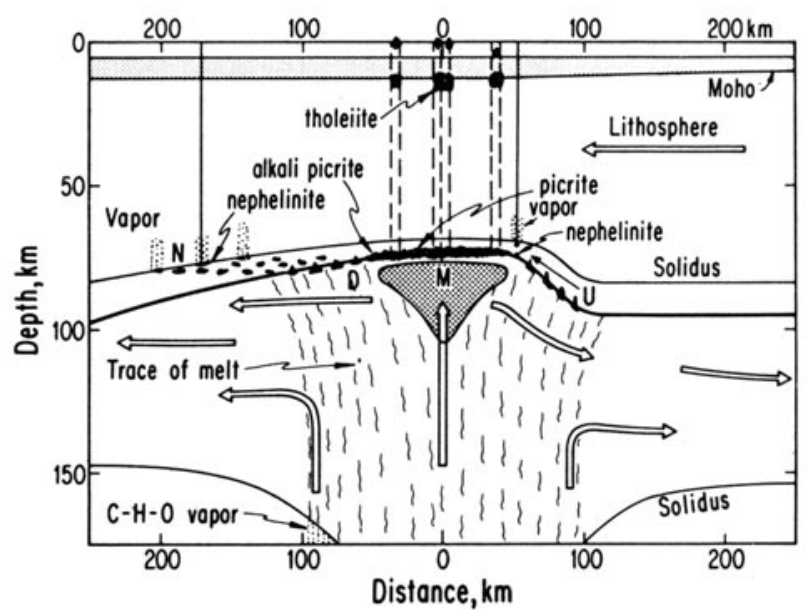

Figure 7. Petrological structure of lithosphere and upper plume corresponding to figure 6, with expanded vertical scale. Picrite magmas enter lithosphere from the melting region $\mathbf{M}$. Volatile-charged magmas enter the lithosphere on both sides of $\mathbf{M}$, with subsequent upward percolation retarded. As they approach the solidus, vapour is evolved (e.g. at $\mathrm{N}$ ) enhancing the prospect of eruption directly through the lithosphere; paths followed by these magmas differ according to their position on the upstream (U) or downstream (D) side of the plume (Wyllie 1988b).

ed channels and flow easily, associated with compaction of the rock matrix. The vapours, in contrast, have interfacial angles greater than $60^{\circ}$ and would remain sealed in blebs unless they were released through fracture. It is likely, therefore, that vapours would rise at the same rate as the plume, but as soon as they crossed the solidus boundary, the trace of melt formed would rise faster than the rock matrix of the plume.

The volatile-rich melt in the central part of the plume is incorporated into the major melting region $\mathbf{M}$. The volatile-rich melt (with composition probably approximating basanite, or nephelinite) in the outer sheath of the plume percolates directly into the lithosphere. What happens to it there depends on the physics of rock-fluid systems and the thickness of the lithosphere. Figure 7 shows an enlarged version of the upper part of the plume of figure 6 , with vertical scale expanded by a factor of two. If the rheological change from asthenosphere to lithosphere retards percolation of the melt, the processes illustrated in figure 7 may yield late nephelinitic eruptions $(\mathrm{N})$ in volcanic islands.

\subsection{Volcanic eruption sequence}

Consider now the magmatic sequence of events that should occur above a thermal plume with this structure, with Hawaii as an example. The oceanic plate crosses the plume from right to left. The first event is the possible eruption of basanite or nephelinite, on the ocean floor. This is soon covered by massive eruptions of tholeiite, derived from picrite formed just below the lithosphere. Before and after the tholeiites there are modest eruptions of alkali basalts derived from the sides of the melting region, $M$. Those following the tholeiites may be separated from the tholeiite by a time interval, because the flow of the plate tends to carry the alkali picrite away from the main plume center. The traces of basanite or nephelinite that enter the lithosphere 
to the left of the plume, on the downstream side of the plate movement, may perhaps be carried away through $100 \mathrm{~km}$ or so before the melt approaches the solidus. The combination of magma pressure and the release of vapours may enhance crack propagation, and allow eruption of nephelinite directly to the surface, from a position such as $\mathbf{N}$ in figure 7. These represent late minor eruptions into an older tholeiite volcano after it has been carried $100 \mathrm{~km}$ from the plume center, like the lavas of the Salt Lake crater on the Hawaiian island of Oahu.

Isotope and trace element studies of the Hawaiian lavas indicate that there is a variety of source rocks contributing to the magmas.

\subsection{Plumes in different tectonic environments}

The same arrangement of phase volumes, an outer sheath with traces of vapour, a core with a trace of volatile-rich melt, and a shallow kernel with extensive melting must occur in all three tectonic environments listed above, but with significant differences imposed by different thicknesses of lithosphere, and associated temperature differences. The major melting region corresponding to $M$ which provides basaltic or picritic magma occurs at different depths in different environments.

Figures 2 and 5 show that beneath an oceanic plate of thickness about $100 \mathrm{~km}$ (figure 6), the temperature of the asthenosphere at $100 \mathrm{~km}$ depth must reach about $1500^{\circ} \mathrm{C}$. Beneath mid-oceanic ridges where the lithosphere is much thinner, melting is associated with vigorous upwelling to the solidus cusp near $10 \mathrm{~kb}$ between plagiociase- and spinel-peridotite, at temperatures of about $1300^{\circ} \mathrm{C}$ (figure 5).

Beneath continental shields where the lithosphere may be $200 \mathrm{~km}$ thick, temperatures in the plume center would have to reach at least $1700^{\circ} \mathrm{C}$ for volatile-free melting to occur (figure 5). The generation of basalts from below continental shields therefore requires significant asthenospheric upwelling and thinning of the lithosphere, probably associated with continental rifting.

The traces of volatile-rich melt in the sheath marginal to the plume is carbonatitic in composition near the solidus, becoming enriched in silicate components with increasing temperature (and perhaps with depth). Beneath oceanic plates, figure 7 illustrates how this melt may reach the surface as nephelinitic lavas. Beneath continental cratons, the kimberlitic melt is trapped temporarily in the $200 \mathrm{~km}$ keel of the lithosphere before some of it escapes to the surface in diatremes. Beneath continental rifts, thinning of the lithosphere to $100 \mathrm{~km}$ or less reproduces the $\mathrm{P}-\mathrm{T}-\mathrm{X}$ conditions similar to those near $\mathrm{N}$ in figure 5 , and the volatiles are involved in the formation of nephelinites and melilitites, with subsequent differentiation to carbonatites.

\section{Metasomatism and global processes}

The carbonatitic and low-SiO $\mathrm{S}_{2}$ melts in the partially melted core of uprising mantle are strongly enriched in incompatible trace elements including radioactive isotopes, and these melts constitute one major cause of mantle metasomatism. The nature of the metasomatism varies according to the presence of a carbonatitic melt, or a silicate melt, or vapours given off during crystallization at depth of these melts. The vapours must be $\mathrm{H}_{2} \mathrm{O}$-rich at depths greater than about $75 \mathrm{~km}$, but they may become $\mathrm{CO}_{2}$-rich 
at shallower depths. These facts have been determined from experimental petrology, but precise details are still needed on the partition of isotopes and trace elements among these various phases and the host rocks.

The history of the traces of vapour and volatile-rich melt in rising mantle plays an important role in determining the distributions of isotopes and trace elements in rocks of the upper mantle and crust. Interpretation of these isotope and trace element systematics in turn is critical for understanding (i) rock reservoirs in mantle, (ii) mantle convection, (iii) the source materials for igneous products, and (iv) the evolution of continents. This fact demonstrates the interdependence of seismic tomography, fluid dynamics, geochemistry and experimental petrology on all scales.

\section{Acknowledgements}

This research was supported by the Earth Science Section of the US National Science Foundation (grant EAR87-19792) and the California Institute of Technology, Division of Geological and Planetary Sciences contribution 4837.

\section{References}

Courtney R C and White R S 1986 Anomalous heat flow and geoid across the Cape Verde Rise: evidence for dynamic support from a thermal plume in the mantle; Geophys. J. R. Astron. Soc. 87 815-867

Takahashi E 1986 Melting of dry peridotite KLB-1 up to $14 \mathrm{GPa}$ : implications on the origin of peridotitic upper mantle; J. Geophys. Res. 91 9367-9382

Wyllie P J 1984 Constraints imposed by experimental petrology on possible and impossible magma sources and products; Philos. Trans. R. Soc. London A310 439-456

Wyllie P J 1988a Magma genesis, plate tectonics, and chemical differentiation of the Earth; Rev. Geophys. 26 370-404

Wyllie P J 1988b Solidus curves, mantle plumes, and magma generation beneath Hawaii; J. Geophys. Res. 93 4171-4181 